\title{
Research Article \\ Elevated LDL-C combined with hypertension worsens subclinical vascular impairment and cognitive function
}

\author{
^Katalin Réka Kovács, MD ${ }^{\mathrm{a}, *},{ }_{\perp}$ Zoltán Bajkó, MD, PhD ${ }^{\mathrm{b}},{ }_{\perp}$ Csilla Cecília Szekeres, MD ${ }^{\mathrm{c}}$, \\ Krisztina Csapó, MD ${ }^{\mathrm{a}},{ }_{\perp}$ László Oláh, MD, PhD ${ }^{\mathrm{a}}$, Mária Tünde Magyar, MD, PhD ${ }^{\mathrm{a}}$,

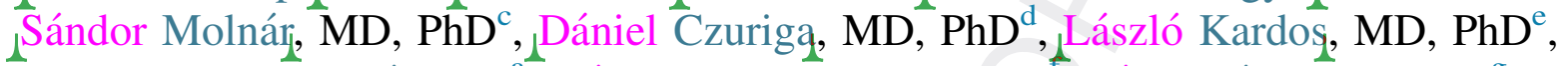 \\ ${ }_{\perp}$ Andrea Bojtor Burainé, MSc ${ }^{a},{ }_{\perp}$ Dániel Bereczkj, MD, DSc ${ }^{\perp},{ }_{\perp}$ Pál Soltész_, MD, DSc $^{g}$, and \\ ${ }_{\perp}$ László Csibą, MD, DSc ${ }^{a}$ \\ ${ }^{a}$ Department of Neurology, University of Debrecen, Debrecen, Hungary; \\ ${ }^{b}$ Department of Neurology, Mureş County Clinical Emergency Hospital, Târgu-Mureş, Romania; \\ ${ }^{c}$ Department of Neurology, Elisabeth Teaching Hospital of Sopron, Sopron, Hungary; \\ ${ }^{d}$ Institute of Cardiology, University of Debrecen, Debrecen, Hungary; \\ ${ }^{e}$ Contract Medical Statistician, Kenézy Gyula Hospital, Debrecen, Hungary; \\ ${ }^{f}$ Department of Neurology, Semmelweis University, Budapest, Hungary; and \\ ${ }^{g}$ Third Department of Medicine, Institute for Internal Medicine, University of Debrecen, Debrecen, Hungary \\ Manuscript received February 16, 2014 and accepted April 14, 2014
}

\section{Abstract}

Hypertension and dyslipidemia belong to the most prevalent modifiable risk factors for cerebrovascular and cardiovascular diseases. Hereby, we aimed to examine the combined effects of newly diagnosed hypertension and hyperlipidemia on the characteristics of the arterial wall and on cognitive function. We examined 72 hypertensive and 85 apparently healthy individuals. Based on serum lipid levels, four subgroups were created ranging from normotensive-normolipidemic to hypertensivehyperlipidemic subjects. Carotid intima-media thickness (IMT), arterial stiffness, and cognitive function were assessed. IMT of controls was the lowest, whereas that of patients with both risk factors the highest. Stiffness parameters increased when both risk factors were present, whereas subjects with only one risk factor exhibited intermediate values. Hypertensive patients performed worse when memory, attention, reaction time, and trait anxiety were assessed. Significant worsening of IMT, arterial stiffness, and sum of neuropsychological scores was observed along with increasing mean arterial pressure. Generally, hyperlipidemia combining with hypertension resulted in further worsening of all examined parameters. Subclinical changes of the vascular wall and cognitive performance are already present in recently diagnosed hypertensive patients. Combination of hyperlipidemia and hypertension results in more severe impairments, therefore, early and intensive treatment may be crucial to prevent further deterioration. J Am Soc Hypertens 2014; (ם):1-11. (C) 2014 American Society of Hypertension. All rights reserved.

Keywords: Arterial stiffness; cardiovascular risk factors; intima-media thickness; neuropsychological performance.

Q3 Grant support: This research was partially supported by the TÁMOP 4.2.1./B-09/1/KONV-2010-0007 project. The project is ${ }_{24} \mathrm{QS}_{\mathrm{C}} \mathrm{CO}-\mathrm{financed}$ by the European Union and the European Social Fund.

Disclosures: The authors report no disclosures.

Conflict of interest: None.

*Corresponding author: Katalin Réka Kovács, MD, Department of Neurology, University of Debrecen, Móricz Zsigmond krt. 22., 4032 Debrecen, Hungary. Tel.: +36-52-255-255; fax: +36-52-453-590.

E-mail: kovacskatireka@yahoo.com

\section{Introduction}

Hypertension is one of the most important modifiable risk factors for cerebrovascular diseases resulting in severe target organ damage. The risk of cardiovascular diseases increases continuously as blood pressure (BP) rises from levels that are considered to be within the normal range. ${ }^{1}$ Based on previous observations, the higher the $\mathrm{BP}$, the greater the risk of stroke, and this correlation can be applied in the nonhypertensive range as well. ${ }^{2}$ In addition, hypertension has also been implicated in the development of impaired cognitive 
106

107

108

109

110

111

112

113

114

115

116

117

118

119

120

121

122

123

124

125

126

127

128

129

130

131

132

133

134

135

136

137

138

139

140

141

142

143

144

145

146

147

148

149

150

151

152

153

154

155

156

157

158

159

160 function. Clinical trials and observational studies showed that lowering BP to $<140 / 90 \mathrm{~mm} \mathrm{Hg}$ decreases morbidity and mortality, although it improves quality of life by preserving cognitive function. One of the greatest benefits of hypertension control is the reduction of stroke risk, which is the strongest contributor to dementia and cognitive function decline. ${ }^{3}$ Besides the possible neuropsychological deterioration caused by hypertension, other feared complications of long-lasting high BP are also well known. Although major clinical events such as stroke or heart attack usually happen after long periods of uncontrolled hypertension, subtle target organ damage such as left ventricular hypertrophy, microalbuminuria, or milder cognitive dysfunction takes place early in the course of hypertension. ${ }^{4}$

Hypercholesterolemia is also a highly prevalent, modifiable risk factor for vascular diseases. Elevated low-density lipoprotein cholesterol (LDL-C) is central to the development and progression of atherosclerosis. ${ }^{5}$ Without any clinical symptoms, atherosclerosis can already be in an advanced stage in hyperlipidemic patients. ${ }^{6}$ Large, population-based studies demonstrated previously that hyperlipidemia, particularly hypercholesterolemia, is associated with the risk of subsequent occurrence of mild cognitive impairment, particularly in middle age. ${ }^{7-9}$ High cholesterol is often a prerequisite for atherosclerotic plaque formation. ${ }^{10}$ Consequently, atherosclerosis and dyslipidemia have become primary targets of intervention in strategies for preventing vascular events. ${ }^{11,12}$

In the present study, we examined the combined effect of hypertension and elevated LDL-C level on the morphologic and functional properties of the arterial wall, represented by intima-media thickness (IMT) and arterial stiffness parameters, respectively. The influence of the two risk factors on cognitive function was also evaluated. Our aims were to (1) detect early changes in the morphologic and functional parameters of the arterial wall caused by early-stage hypertension, (2) analyze whether these changes are more pronounced when hypertension is combined with hyperlipidemia, and (3) evaluate neuropsychological performance in the patient groups.

\section{Methods}

\section{Subjects}

Ninety-four recently diagnosed hypertensive patients were screened during the study period. From the initial database, 16 patients were excluded because of diabetes, chronic diseases, or lack of compliance. To guard against the confounding effects of possible long-standing, asymptomatic BP elevation, 6 patients were further excluded from the study, in whom explicit target organ damage could be identified by urine analysis (microalbuminuria or macroalbuminuria), echocardiography (left ventricular hypertrophy), cerebral computed tomography (silent brain infarction), or fundoscopic examination (advanced retinopathy). Finally, 72 recently diagnosed hypertensive patients (mean age \pm standard error of the mean [SEM], $43.60 \pm 1.20$ years; male/female ratio, $0.95)$ were recruited in the study cohort. The control group consisted of 85 apparently healthy individuals (mean age \pm SEM, $43.56 \pm 0.97$ years; male/female ratio, 1.13). The study was approved by the local Ethical Committee of the University of Debrecen. Informed consent was obtained from all patients and controls.

Based on the serum LDL-C level (higher or lower than $3.4 \mathrm{mmol} / \mathrm{L}$ [the upper normal limit of LDL-C level according to our laboratory reference values]), the control and hypertensive groups were further divided, resulting in four subgroups (1) healthy controls, free of hypertension or hyperlipidemia $(\mathrm{CON} ; \mathrm{n}=44$; mean age $\pm \mathrm{SEM}$, $42.5 \pm 1.36$ years; male/female ratio, 1 ); (2) normotensive subjects with elevated LDL-C levels (LDL; $\mathrm{n}=41$; mean age $\pm \mathrm{SEM}, 44.71 \pm 1.38$ years; male/female ratio, 1.28 ); (3) hypertensive patients with normal LDL-C levels (HT; $\mathrm{n}=49$; mean age \pm SEM; $41.67 \pm 1.47$ years; male/female ratio, 0.75); and (4) hypertensive patients with elevated LDL-C levels (HT + LDL; $\mathrm{n}=23$; mean age \pm SEM, $47.70 \pm 1.83$ years; male/female ratio, 1.56 ).

\section{Measurements}

The following examinations were performed in all groups: BP measurement, laboratory analysis, IMT measurement of the common carotid arteries (CCAs), assessment of arterial stiffness parameters, and neuropsychological testing.

\section{BP Measurement}

Primary diagnosis of hypertension was made by family doctors and internists based on international guidelines. ${ }^{13}$ During our study protocol, office measurements of systolic, diastolic, and mean arterial BPs served the purpose of data collection. To this end, we applied an arteriograph medical device (TensioClinic Arteriograph, TL1; TensioMed Ltd, Hungary), which uses a standard oscillometric technique to determine BP values in $\mathrm{mm} \mathrm{Hg}$. Measurements were performed in supine position using a cuff placed on the resting right arm with its lower edge located $\sim 25 \mathrm{~mm}$ above the elbow and the air outlet directly above the brachial artery.

\section{Laboratory Analysis}

Fasting blood samples were taken for serum glucose, lipids, and kidney function. The measured parameters were part of the routine examination performed by the Department of Laboratory Medicine, University of Debrecen. Quality assurance of the laboratory was based on daily internal control and also on participation in external quality control programs.

\section{IMT Measurement}

High-resolution B-mode carotid ultrasonography was performed using a 7.5 MHz SonoSite MicroMaxx ultrasound 
machine (SonoSite Inc, Bothell, WA, USA). Patients were examined in supine position with the head turned 45 away from the side being scanned. Measurements were performed in plaque free regions on the far wall of both CCAs $\sim 1-\mathrm{cm}$ proximal to the carotid bulb. IMT was defined as the distance between the luminal endothelial interface and the junction between the media and the adventitia. On examination, $\mathrm{R}$ waves-triggered longitudinal B-mode images were recorded, saved, and stored for later offline analysis. Six measurements per vessel were taken on both sides, and IMT data of the two CCAs were averaged.

\section{Arterial Stiffness}

Measurements were performed with a validated, computerized portable device (TensioClinic Arteriograph, TL1). ${ }^{14,15}$ Pulse wave velocity (PWV, in $\mathrm{m} / \mathrm{s}$ ) and brachial augmentation index (AIx, in \%) were determined by analyzing the oscillometric pressure curves registered on the upper arm. ${ }^{16}$

\section{Neuropsychological Examination}

All participants completed a 1-hour ( \pm 10 minutes) neuropsychological test series assessing reaction time, memory, attention, executive function, psychomotor speed, visual-spatial ability, anxiety, and depression. ${ }^{17}$ The applied tests, previously used by several authors, ${ }^{18-32}$ can reveal such minor alterations of the cognitive function, which are not necessarily evident during everyday activity. All tests were carried out and scored by a trained psychologist.

\section{Statistical Analysis}

Vascular and neuropsychological parameters (outcomes) were described using standard statistics and compared between groups with no adjustment using parametric or nonparametric tests as appropriate for distributional characteristics. Associations between factors and outcomes were assessed using multiple linear regression adjusted for age, sex, smoking status (all models), level of education (neuropsychological outcomes only; patients with college and/or university degrees qualified for the category of higher education, patients with a maximum of 12 years of education [primary school or primary and secondary schools] qualified for lower education category), mean arterial pressure (MAP; unless BP was an explanatory or outcome variable), and serum LDL-C level (unless lipid level was an explanatory or outcome variable). Effects of categorical factors were expressed as expected values of between group differences with 95\% confidence intervals and $P$ values. Effects of continuous variables were calculated for a single unit increase and expressed similarly. Interactions between hypertension and hyperlipidemia, and between hypertension and level of education were evaluated for potential improvement of model fit.

\section{Results}

\section{Clinical Data}

Clinical data are presented in Table 1 . None of the patients had chronic kidney disease or diabetes. There was no difference between the groups regarding gender, smoking habit, fasting blood glucose, and creatinine levels. In the hypertensive group, $29.2 \%$ of patients declared to be an active or former smoker, whereas in the normotensive group, this ratio was $21.2 \%$. Among hypertensive patients, 44.4\% declared moderate level alcohol consumption, 5.5\% admitted regular alcohol intake, whereas $48.6 \%$ were abstinent to alcohol. These ratios in the normotensive group were $60 \%, 11.7 \%$, and $24.7 \%$, respectively.

\section{Intima-media Thickness}

Despite IMT being in the normal range in all four groups, during unadjusted comparison IMT was significantly higher in the HT group compared with CON $(0.60 \pm 0.01$ vs. $0.53 \pm 0.01 \mathrm{~mm} ; P=.0005)$ or LDL groups $(0.60 \pm 0.01$ vs. $0.55 \pm 0.01 \mathrm{~mm} ; P=.0142)$. A further increase of borderline significance in the IMT value was found when hypertension was associated with elevated LDL-C levels $(0.60 \pm 0.01$ vs. $0.67 \pm 0.03 \mathrm{~mm}$ for $\mathrm{HT}$ and $\mathrm{HT}+\mathrm{LDL}$, respectively; $P=.0505$; Figure 1A). Adjusted comparison of subjects with hyperlipidemia (LDL, HT + LDL) to subjects with normolipidemia (CON, HT) revealed no significant difference in IMT values. However, when performing subgroup comparison between hypertensive (HT, HT + LDL) and normotensive subjects (CON, LDL) using multiple regression, the difference in the IMT values remained significant $(0.62 \pm 0.01$ vs. $0.54 \pm 0.01 \mathrm{~mm} ; P<.0001)$. Furthermore, during the analysis of the adjusted effect of MAP, we found a significant increase of $0.0019 \mathrm{~mm}$ in the expected IMT value for each $\mathrm{mm} \mathrm{Hg}$ increase in $\mathrm{MAP}(P=.0038)$.

\section{Stiffness Parameters}

Raw comparisons revealed a significantly increased AIX ${ }^{27}$ value in the HT and LDL groups compared to CON $(-30.37 \pm 3.39$ vs. $-15.50 \pm 4.85 \% ; P=.0284$ or $-18.36 \pm 4.36 \% ; P=.0311$, respectively). Hyperlipidemia coexisting with hypertension further increased AIx values, thus comparison between the HT $+\mathrm{LDL}$ and CON groups resulted in an even greater difference $(-10.43 \pm 5.97$ vs. $-30.37 \pm 3.39 \% ; P=.0026$; Figure 1B). When subjects with hyperlipidemia versus normolipidemia were compared using multiple regression, no significant difference was found in the AIx values. In contrast, adjusted comparison of hypertensive and normotensive participants revealed a significant difference $(-14.39 \pm 3.61$ vs. $-24.12 \pm 2.76 \%$, respectively; $P=.0023$ ).

Value of PWV was the lowest in CON, whereas highest in the HT + LDL group. PWV values of those participants with 
Table 1

Clinical data of the participants

\begin{tabular}{|c|c|c|c|c|c|}
\hline Variable & $\mathrm{CON}(\mathrm{N}=44)$ & $\operatorname{LDL}(\mathrm{N}=41)$ & HT (N = 49) & $\begin{array}{l}\mathrm{HT}+\mathrm{LDL} \\
(\mathrm{N}=23)\end{array}$ & $P$ Value \\
\hline Age (years) & $42.5 \pm 1.36^{\mathrm{a}}$ & $44.71 \pm 1.38$ & $41.67 \pm 1.47^{\mathrm{b}}$ & $47.70 \pm 1.83^{\mathrm{a}, \mathrm{b}}$ & a. $0271,{ }^{\text {b }} .0181$ \\
\hline BMI $\left(\mathrm{kg} / \mathrm{m}^{2}\right)$ & $24.49 \pm 0.60^{\mathrm{a}, \mathrm{b}, \mathrm{c}}$ & $26.23 \pm 0.57^{\mathrm{a}}$ & $26.90 \pm 0.55^{\mathrm{b}}$ & $27.95 \pm 0.71^{\mathrm{c}}$ & ${ }^{\mathrm{a}} .0396,{ }^{\mathrm{b}} .0039,{ }^{\mathrm{c}} .0007$ \\
\hline $\begin{array}{l}\text { Non/active or former } \\
\text { smoker }\end{array}$ & $35 / 9$ & $31 / 9$ & $32 / 17$ & $19 / 4$ & NS \\
\hline MAP (mm Hg) & $92.21 \pm 1.48^{\mathrm{a}, \mathrm{b}}$ & $93.48 \pm 1.29^{\mathrm{c}, \mathrm{d}}$ & $102.40 \pm 1.69^{\mathrm{a}, \mathrm{c}, \mathrm{e}}$ & $108.36 \pm 2.35^{\mathrm{b}, \mathrm{d}, \mathrm{e}}$ & ${ }^{\mathrm{a}, \mathrm{b}, \mathrm{d}}<.0001,{ }^{\mathrm{c}} .0001,{ }^{\mathrm{e}} .047$ \\
\hline SBP (mm Hg) & $126.60 \pm 2.01^{\mathrm{a}, \mathrm{b}}$ & $126.5 \pm 2.13^{\mathrm{c}, \mathrm{d}}$ & $138.81 \pm 2.34^{\mathrm{a}, \mathrm{c}}$ & $143.82 \pm 3.14^{\mathrm{b}, \mathrm{d}}$ & ${ }^{\mathrm{a}, \mathrm{c}} .0002,{ }^{\mathrm{b}, \mathrm{d}}<.0001$ \\
\hline DBP (mm Hg) & $75.09 \pm 1.41^{\mathrm{a}, \mathrm{b}}$ & $76.98 \pm 1.32^{\mathrm{c}, \mathrm{d}}$ & $84.17 \pm 1.58^{\mathrm{a}, \mathrm{c}, \mathrm{e}}$ & $90.64 \pm 2.16^{\mathrm{b}, \mathrm{d}, \mathrm{e}}$ & ${ }^{\mathrm{a}} .0001,{ }^{\mathrm{b}, \mathrm{d}}<.0001,{ }^{\mathrm{c}} .001,{ }^{\mathrm{e}} .0215$ \\
\hline FBG (mmol/L) & $5.05 \pm 0.10$ & $5.25 \pm 0.08$ & $5.10 \pm 0.08$ & $5.33 \pm 0.12$ & NS \\
\hline $\mathrm{T}-\mathrm{C}(\mathrm{mmol} / \mathrm{L})$ & $4.77 \pm 0.09^{\mathrm{a}, \mathrm{b}}$ & $6.18 \pm 0.11^{\mathrm{a}, \mathrm{c}}$ & $4.78 \pm 0.11^{\mathrm{c}, \mathrm{d}}$ & $6.37 \pm 0.11^{\mathrm{b}, \mathrm{d}}$ & $\mathrm{a}, \mathrm{b}, \mathrm{c}, \mathrm{d}<.0001$ \\
\hline
\end{tabular}

BMI, body mass index; CON, healthy controls; FBG, fasting blood glucose; HDL-C, high-density lipoprotein cholesterol; HT, hypertensive patients; HT + LDL, hypertensive patients with elevated low-density lipoprotein cholesterol level; LDL, subjects with elevated lowdensity lipoprotein cholesterol level; LDL-C, low-density lipoprotein cholesterol; MAP, mean arterial blood pressure; NS, not significant; SBP, systolic blood pressure; T-C, total cholesterol; TG, triglyceride.

Data are presented as means \pm standard error of the mean, percentage (for male/female ratio) or as absolute numbers (for smoking status and education).

$\mathrm{a}, \mathrm{b}, \mathrm{c}, \mathrm{d}$, and e indicate affiliated group comparisons of corresponding $P$ values.

only one risk factor were intermediate. Unadjusted estimations showed a significant difference between PWV values of CON and HT groups $(8.01 \pm 0.21$ vs. $9.64 \pm 0.40 \mathrm{~m} / \mathrm{s}$, respectively; $P=.0029)$. Likewise, $\mathrm{PWV}$ values were further increased in the group of patients with both risk factors, therefore the differences between HT + LDL and CON or LDL groups were also significant (10.02 \pm 0.35 vs. $8.01 \pm 0.21 \mathrm{~m} / \mathrm{s} ; P<.0001$ or $8.79 \pm 0.41 \mathrm{~m} / \mathrm{s} ; P=.0019$, respectively; Figure 1C). Adjusted comparison of subjects with hyperlipidemia versus normolipidemia resulted in no significant difference. However, when hypertensive and normotensive participants were compared, significantly higher values were observed in association with hypertension $(9.74 \pm 0.28$ vs. $8.46 \pm 0.23 \mathrm{~m} / \mathrm{s} ; P<.0001)$.

While analyzing the adjusted effect of LDL-C level on arterial stiffness parameters, we found no significant effect. However, MAP-adjusted effect on arterial stiffness parameters showed a significant elevation of $0.50 \%$ in the expected value of $\operatorname{AIx}(P=.0004)$ and a significant elevation of $0.058 \mathrm{~m} / \mathrm{s}$ in the expected value of PWV $(P<.0001)$ for each $\mathrm{mm} \mathrm{Hg}$ increase in MAP.

\section{Neuropsychological Performance}

\section{Cognitive Battery}

Detailed presentation of the applied tests and group comparisons are shown in Table 2. Adjusted comparison of normotensive versus hypertensive participants resulted in significant differences when assessing choice reaction time or memory and attention with the digit span test $(P=.0405$ and $P=.0002$ for choice reaction time and digit span test, respectively; data not shown). Sum of standardized test scores (SSTS), which comprises the results of all neuropsychological tests (except questionnaires assessing anxiety and depression), revealed a tendency as follows: subjects with no risk factor reached the highest, whereas patients with both risk factors the lowest scores. For the two other groups intermediate values were observed. During unadjusted comparison significant difference in SSTS could be detected between the CON and HT or HT + LDL groups $(1.97 \pm 0.59$ vs. $0.02 \pm 0.64 ; P=.0285$ or $-0.51 \pm 1.13$; $P=.0413$, respectively; Figure 2). Although the adjusted between-groups comparison revealed a strong, but nonsignificant tendency for hypertensive patients to reach lower scores compared with normotensive subjects $(-0.27 \pm 0.59$ vs. $1.37 \pm 0.46$, respectively; $P=.1015)$, the assessment of the adjusted effect of MAP on SSTS resulted in a significant reduction of 0.1169 in the expected score for each $\mathrm{mm} \mathrm{Hg}$ increase in MAP $(P<.0001)$.

\section{Anxiety and Depression}

Although Spielberger state anxiety scores revealed no significant differences between the groups, unadjusted comparison of Spielberger trait inventory revealed significantly 

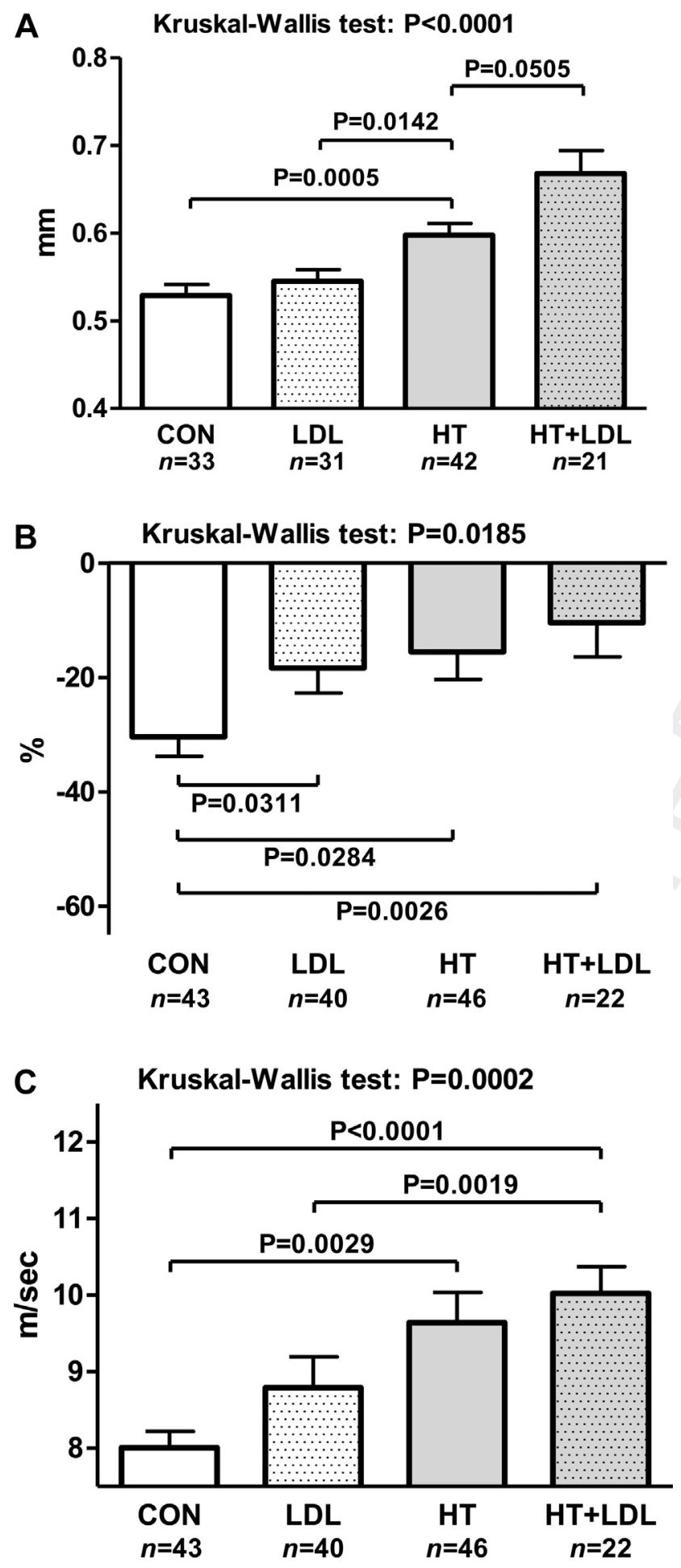

Figure 1. Unadjusted comparisons of morphologic and functional parameters of the vascular wall in the four groups. (A) Intima-media thickness values (in mm). (B) Augmentation Index values (in \%). (C) Pulse wave velocity values (in $\mathrm{m} / \mathrm{s}$ ). Columns show means \pm standard error of the mean. $\mathrm{CON}$, healthy controls; LDL, subjects with elevated low-density lipoprotein cholesterol level; HT, hypertensive patients; HT + LDL, hypertensive patients with elevated low-density lipoprotein cholesterol level; n: number of subjects. higher scores in the HT group compared with $\mathrm{CON}$ (39.56 \pm 1.27 vs. $33.42 \pm 1.10 ; P=.0005)$. Moreover, a further increase of scores was found, when hypertension associated with elevated LDL-C levels $(41.38 \pm 2.03$ vs. $33.42 \pm 1.10 ; P=.0009$ or $37.11 \pm 1.62 ; P=.0456$ for HT + LDL and CON or LDL, respectively). When analyzing the difference between hypertensive and normotensive participants with multiple regression, significantly higher Spielberger trait anxiety scores were observed in hypertensive patients $(39.68 \pm 1.04$ vs. $35.15 \pm 0.97 ; P=.0014)$. Although patients with both risk factors reached the highest score during Beck depression inventory, there was no significant difference between the groups either in unadjusted, or in adjusted models.

Adjusted effect of MAP and that of LDL-C on the different studied parameters are summarized in Table 3.

\section{Discussion}

This study revealed that subtle changes of vascular wall properties and that of cognitive function are already present in recently diagnosed hypertensive patients. Analysis of the adjusted effect of MAP shed light on the gradual elevation of IMT, AIx, and PWV values with increasing BP, which certifies the causative role of hypertension in these early morphologic and functional alterations of the vasculature. Regarding cognitive performance, there was a clear tendency as follows: healthy subjects reached the highest, whereas patients with both risk factors the lowest scores, when SSTS was evaluated. The level of anxiety also tended to be higher in the presence of risk factors. Although hyperlipidemia per se did not result in significant worsening of the previously mentioned parameters, when it was associated with hypertension, more pronounced impairments could be observed.

Pall et al. ${ }^{33}$ previously demonstrated that IMT values of the CCA were higher in hypertensive adolescents compared with healthy controls, suggestive of ongoing target organ damage in young patients with short-lasting hypertension. Accordingly, we also observed significantly higher IMT values in early-stage hypertensive adults in their mid-40s when compared with controls. In addition, Amer et al. ${ }^{34}$ recently found that hypertension duration was positively correlated with IMT among senescent hypertensive patients. These findings indicate that hypertension leads to higher IMT values of the arterial wall in all ages.

In our study population, the increasing number of risk factors induced more explicit changes. When analyzing LDLC-adjusted effects, we found no significant differences between the groups. This observation suggests that although hyperlipidemia is definitely a contributing factor to the deterioration of the vascular system, per se it may not yet result in detectable changes at this early stage. In contrast with our results, when Vladimirova-Kitova et al. ${ }^{35}$ evaluated IMT in asymptomatic, nontreated, severe hypercholesterolemic 
Table 2

Group comparisons on neuropsychological test performance

\begin{tabular}{|c|c|c|c|c|c|c|}
\hline Neurospychological Test & Function & $\mathrm{CON}(\mathrm{n}=43)$ & $\operatorname{LDL}(\mathrm{n}=39)$ & $\mathrm{HT}(\mathrm{n}=46)$ & $\begin{array}{l}\mathrm{HT}+\mathrm{LDL} \\
(\mathrm{n}=22)\end{array}$ & $P$ Value \\
\hline Choice Reaction Time (s) & Reaction time & $0.52 \pm 0.01^{\mathrm{a}, \mathrm{b}}$ & $0.54 \pm 0.01$ & $0.56 \pm 0.01^{\mathrm{a}}$ & $0.56 \pm 0.02^{\mathrm{b}}$ & ${ }^{\mathrm{a}} .0105,{ }^{\mathrm{b}} .011$ \\
\hline $\begin{array}{l}\text { Selective Reaction } \\
\text { Time (s) }\end{array}$ & Reaction time & $0.62 \pm 0.01$ & $0.65 \pm 0.01$ & $0.65 \pm 0.02$ & $0.64 \pm 0.03$ & NS \\
\hline RAVLT score & Memory & $13.19 \pm 0.38$ & $13.05 \pm 0.42$ & $12.28 \pm 0.44$ & $11.48 \pm 0.86$ & NS \\
\hline First Recognition score & Memory & $12.55 \pm 0.30^{\mathrm{a}}$ & $11.69 \pm 0.32^{\mathrm{a}}$ & $11.67 \pm 0.33$ & $11.82 \pm 0.59$ & ${ }^{\mathrm{a}} .0117$ \\
\hline Pieron Test $(\%)$ & $\begin{array}{l}\text { Attention and } \\
\text { vigilance }\end{array}$ & $91.61 \pm 1.16$ & $93.46 \pm 0.87^{\mathrm{a}}$ & $92.59 \pm 1.20^{\mathrm{b}}$ & $86.12 \pm 3.08^{\mathrm{a}, \mathrm{b}}$ & ${ }^{\mathrm{a}} .0146,{ }^{\mathrm{b}} .0174$ \\
\hline $\begin{array}{l}\text { Trail Making Test, } \\
\text { part A (s) }\end{array}$ & $\begin{array}{l}\text { Attention and } \\
\text { vigilance }\end{array}$ & $32.25 \pm 2.11$ & $33.11 \pm 2.49$ & $27.51 \pm 1.67^{\mathrm{a}}$ & $35.95 \pm 3.00^{\mathrm{a}}$ & ${ }^{\mathrm{a}} .0153$ \\
\hline Digit Span Test score* & $\begin{array}{l}\text { Memory, attention } \\
\text { and vigilance }\end{array}$ & $11.70 \pm 0.31^{\mathrm{a}, \mathrm{b}}$ & $11.97 \pm 0.42^{\mathrm{c}, \mathrm{d}}$ & $10.07 \pm 0.30^{\mathrm{a}, \mathrm{c}}$ & $10 \pm 0.54^{\mathrm{b}, \mathrm{d}}$ & $\begin{array}{l}\text { a } .0006,,^{b} .0011, \\
{ }^{c} .0003,{ }^{d} .0034\end{array}$ \\
\hline Block Design Test (s) & $\begin{array}{l}\text { Visuo-spatial and } \\
\text { motor skills }\end{array}$ & $26.07 \pm 0.53$ & $25.28 \pm 0.53$ & $25.67 \pm 0.58$ & $24.9 \pm 0.83$ & NS \\
\hline Digit Symbol Test score & $\begin{array}{l}\text { General processing } \\
\text { speed }\end{array}$ & $52.77 \pm 1.50^{\mathrm{a}}$ & $49.63 \pm 1.43$ & $50.60 \pm 1.34^{\mathrm{b}}$ & $44.33 \pm 2.69^{\mathrm{a}, \mathrm{b}}$ & ${ }^{\mathrm{a}} .0051,{ }^{\mathrm{b}} .0238$ \\
\hline $\begin{array}{l}\text { Spielberger State Anxiety } \\
\text { score }\end{array}$ & Anxiety & $39.47 \pm 1.58$ & $39.55 \pm 1.86$ & $42.09 \pm 1.31$ & $42.36 \pm 2.16$ & NS \\
\hline $\begin{array}{l}\text { Spielberger Trait Anxiety } \\
\text { score }\end{array}$ & Anxiety & $33.42 \pm 1.10^{\mathrm{a}, \mathrm{b}}$ & $37.11 \pm 1.62^{\mathrm{c}}$ & $39.56 \pm 1.27^{\mathrm{a}}$ & $41.38 \pm 2.03^{\mathrm{b}, \mathrm{c}}$ & $\begin{array}{l}{ }^{\mathrm{a}} .0005, \mathrm{~b} .0009, \\
{ }^{\mathrm{c}} .0456\end{array}$ \\
\hline Beck Depression score & Depression & $5.14 \pm 0.68$ & $5.32 \pm 1.02$ & $5.89 \pm 0.96$ & $7.09 \pm 1.46$ & NS \\
\hline
\end{tabular}

CON, healthy controls; HT, hypertensive patients; HT + LDL, hypertensive patients with elevated low-density lipoprotein cholesterol level; LDL, subjects with elevated low-density lipoprotein cholesterol level; RAVLT, Rey Auditory Verbal Learning test; s, second. Qs

Data are presented as means \pm standard error of the mean.

$\mathrm{a}, \mathrm{b}, \mathrm{c}$, and d indicate affiliated group comparisons of corresponding $P$ values.

* Digit span test score comprises forward and backward recalls as well.

subjects, they found that these individuals were at a high risk of having increased IMT, especially if endothelial dysfunction was also present. The discrepancy between these

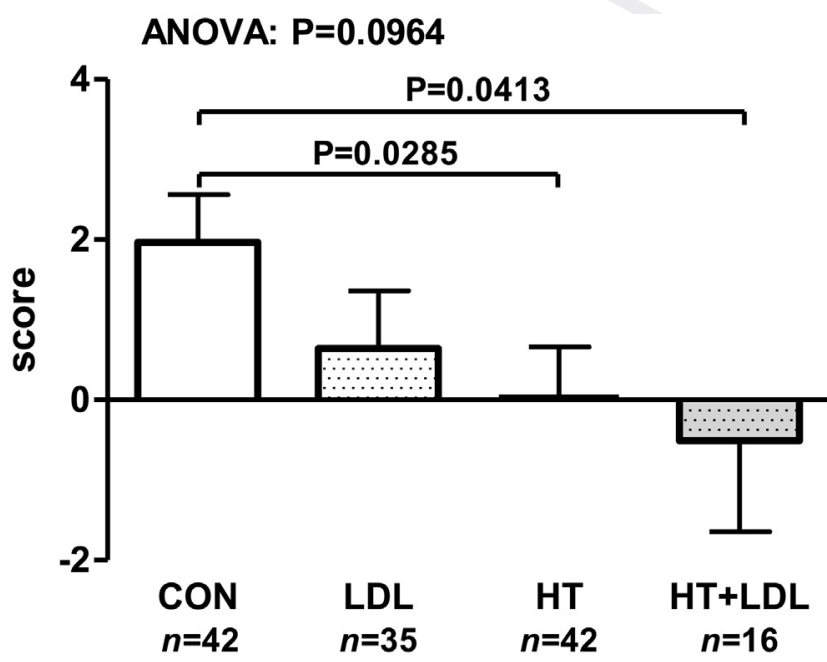

Figure 2. Unadjusted comparisons of the sum of standardized test scores in the four groups. Columns show means \pm standard error of the mean. CON, healthy controls; LDL, subjects with elevated low-density lipoprotein cholesterol level; HT, hypertensive patients; HT + LDL, hypertensive patients with elevated low-density lipoprotein cholesterol level; n: number of subjects. observations may originate from a difference in lipid levels, although our patients had only moderately high levels of LDL-C with an average of $4.13 \pm 0.06 \mathrm{mmol} / \mathrm{L}$ (mean \pm SEM), the population studied by VladimirovaKitova et al. ${ }^{35}$ had severe hyperlipidemia. In another study, Li et al. ${ }^{36}$ observed that over a mean of 10.7 years follow-up, patients with normal $\mathrm{BP}(<140 / 90 \mathrm{~mm} \mathrm{Hg})$ but with carotid artery atherosclerosis (defined as mean IMT $\geq 0.81 \mathrm{~mm}$ and/ or presence of a plaque [IMT $>1.2 \mathrm{~mm}$ ]) had a 3 -fold higher risk of ischemic stroke compared with those with normal carotid arteries. This difference remained significant even when risk was adjusted for age, sex, BP, cholesterol, fasting glucose, and smoking. ${ }^{36}$ These observations emphasize the importance of IMT monitoring, as higher values may draw attention to an increasing stroke risk.

Regarding arterial stiffness, Nürnberger et al. ${ }^{37}$ previously observed that AIx was correlated with age, diastolic $\mathrm{BP}$, heart rate, height, and gender in a population that was free of any atherosclerotic disease. Similarly, in subjects with atherosclerosis, all these parameters were correlated with AIx, with the exception of age. ${ }^{37}$ Accordingly, in our study, we found higher AIx values in hypertensive subjects after adjustment for parameters such as age, gender, serum LDL-C level, and smoking status. At the moment, data regarding the relationship between serum lipid levels and arterial stiffness are controversial. Wilkinson et al. ${ }^{38}$ found 
Table 3

Adjusted effect of mean arterial pressure and that of LDL cholesterol level on variables

\begin{tabular}{|c|c|c|c|c|c|c|}
\hline \multirow[t]{2}{*}{ Variable } & \multicolumn{3}{|c|}{$\begin{array}{l}\text { Adjusted Effect of Mean Arterial Pressure } \\
(\text { Contrast, }+1 \mathrm{~mm} \mathrm{Hg})\end{array}$} & \multicolumn{3}{|c|}{$\begin{array}{l}\text { Adjusted Effect of LDL Cholesterol } \\
\text { (Contrast, }+1 \mathrm{mmol} / \mathrm{L})\end{array}$} \\
\hline & Effect & $95 \% \mathrm{CI}$ & $P$ Value & Effect & $95 \% \mathrm{CI}$ & $P$ Value \\
\hline Augmentation index $(\%)$ & 0.5047 & 0.2302 to 0.7793 & .0004 & 3.0808 & -0.6266 to 6.7882 & .1027 \\
\hline Pulse wave velocity $(\mathrm{m} / \mathrm{s})$ & 0.0580 & 0.0308 to 0.0853 & $<.0001$ & 0.1356 & -0.2321 to 0.5033 & .4673 \\
\hline Choice reaction time (s) & 0.0018 & 0.0008 to 0.0029 & .0008 & 0.0046 & -0.0086 to 0.0178 & .4931 \\
\hline RAVLT score & -0.0537 & -0.0953 to -0.0120 & .012 & 0.1320 & -0.3917 to 0.6558 & .6189 \\
\hline First recognition score & -0.0401 & -0.0732 to -0.0070 & .0181 & 0.0397 & -0.3781 to 0.4574 & .8514 \\
\hline Pieron test $(\%)$ & -0.0985 & -0.2314 to 0.0343 & .1447 & 0.0157 & -1.6380 to 1.6696 & .985 \\
\hline Trail making test (s) & 0.0739 & -0.1305 to 0.2783 & .4756 & 1.7883 & -0.7541 to 4.3306 & .1665 \\
\hline Digit span test score* & -0.0727 & -0.1052 to -0.0402 & $<.0001$ & 0.3781 & -0.0315 to 0.7877 & .0701 \\
\hline Block design test (s) & -0.0434 & -0.0946 to 0.0079 & .0966 & -0.4259 & -1.0733 to 0.2215 & .1955 \\
\hline Spielberger trait anxiety score & 0.0823 & -0.0579 to 0.2224 & .2477 & 0.7739 & -1.0001 to 2.5478 & .3898 \\
\hline Beck depression score & 0.0294 & -0.0619 to 0.1208 & .5248 & 0.6410 & -0.5295 to 1.8116 & .2807 \\
\hline
\end{tabular}

LDL, low-density lipoprotein; RAVLT, Rey Auditory Verbal Learning test; SSTS, sum of standardized test scores; s, second.

* Digit Span test score comprises forward and backward recalls as well.

that patients with hypercholesterolemia had stiffer blood vessels than matched controls, despite their similar peripheral BP values. Although their study showed that stiffness was independently correlated with LDL, ${ }^{38}$ Nürnberger et al. ${ }^{37}$ found no significant association between cholesterol levels and AIx. In agreement with the latter investigator group, we could not demonstrate any significant effect of serum LDL-C level on AIx in our study.

Safar et al. ${ }^{39}$ previously stated that increased aortic PWV is a strong and independent predictor of cardiovascular risk, regardless of whether this mechanical factor plays a causative role or merely serves as a marker of vascular disease already present. It has been shown in a recent study that PWV at any age is related linearly to systolic, whereas symmetrically to any BP level, and is proportional to the square of age. Moreover, after correction for squared age and BP, PWV was not significantly influenced by smoking or lipid status, and gender differences were also negligible. ${ }^{40}$ Likewise, in our study, PWV was significantly higher in hypertensive subjects compared with normotensive ones during multiple regression analysis; however, there was no significant difference between PWV values of normolipidmic versus hyperlipidemic subjects. Based on these observations it is likely that the hypertension- and aging-related vascular stiffness is independent of hyperlipidemia. Previous studies suggest that stiffening of the arterial wall in hypertensive and/or senescent individuals may derive from mechanisms such as fibrosis or calcification induced vascular changes. ${ }^{41-43}$

Of note, numerous investigations justified that changes of IMT and arterial stiffness parameters in hypertensive patients can be improved by various antihypertensive therapies. $^{44-47}$

So far, the relationship between cognitive function and hypertension has been examined by several authors. Debette et al. ${ }^{48}$ evaluated the association of vascular risk factor exposure in midlife with cognitive decline in participants without dementia from the prospective Framingham Offspring Cohort Study. They found that hypertension in midlife was associated with a worsening executive function. ${ }^{48}$ Accordingly, Knecht et al. ${ }^{27}$ found that systolic BP explained up to $11 \%$ of the variance in cognitive performance in nondemented groups of individuals in midlife age, suggesting that in this population hypertension may account for onetenth of cognitive impairment and thus for an increased risk for dementia. Another study performed by Vicario et al. ${ }^{19}$ demonstrated that cognitive impairment of hypertensive patients is present in areas such as attention, memory, and executive function. ${ }^{19}$ While evaluating middle-aged, never-treated hypertensive patients, Sierra et al. ${ }^{49}$ first described that the presence of silent cerebral white matter lesions is associated with a mild decline in basic attention. The previously mentioned findings are in accordance with our results, as our hypertensive patients reached lower scores particularly in tests evaluating memory and attention. In general, we could not demonstrate any significant effect of adjusted LDL-C on cognitive function. Nonetheless, when calculating the SSTS, substantially lower scores could be observed in hypertensive patients, which became even more explicit when both risk factors were present. After all, these early and subtle changes of neuropsychological parameters cannot be noticed during the everyday life of an 
individual. However, they indicate a disturbed cognitive performance in this early stage of hypertension. Several hypotheses have been previously proposed to provide plausible explanation for the pathomechanism of neuropsychological deterioration in the setting of hypertension; structural vascular changes leading to extracellular edema, disruption of the blood-brain barrier, chronic cortical deafferentation resulting in vessel obstruction leading to ischemia, ${ }^{50}$ insufficient cerebral blood flow, ${ }^{51,52}$ disturbed cerebral metabolism, autoregulation or neurochemistry, enhanced cardiovascular and neuroendocrine reactivity, ${ }^{52,53}$ anxiety, ${ }^{54}$ and so forth. Likewise, the pathophysiology of hyperlipidemia-associated cognitive decline has also been thoroughly studied ( $\beta$-amyloid generation, $\tau$-hyperphosphorylation, inflammation in the brain, ${ }^{55,56}$ etc.), but the exact links between cognitive impairment and these two important cerebrovascular and cardiovascular risk factors are yet to be clarified. Importantly, the early cognitive deficit of young hypertensive individuals can be reversed with an appropriate antihypertensive therapy, as suggested by previous findings. ${ }^{24,57-59}$

The association between high BP and anxiety is supported by a large number of case-control studies, which compared either psychological symptoms in hypertensive and control subjects, or BP in patients with a variety of psychiatric disorders and controls. ${ }^{60}$ When examining anxiety disorder, Vetere et al. ${ }^{61}$ found a higher prevalence in hypertensive individuals compared with controls. Our hypertensive patients also reached higher scores on anxiety inventories. Recently it was proposed that anxiety could play an important role in hypertension development through altered autonomic control of the heart. ${ }^{62}$ In another study performed by Paterniti et al. ${ }^{63}$ anxiety was independently-, whereas depression was not, associated with an increased risk for high BP. Although their findings did not permit the establishment of a causal relationship between anxiety and BP, it was suggested that behavioral patterns of anxious patients, such as lifestyle, diets, drinking, smoking, or other habits might play a role as risk factors for high BP development. ${ }^{63}$ After all, it needs further investigations to elucidate whether patients with hypertension are more susceptible to anxiety or rather subjects with anxiety tend to develop hypertension over time.

\section{Conclusions}

Our results provide insight into the early vascular alterations and cognitive disturbance induced by newly diagnosed hypertension and hyperlipidemia. Subclinical changes produced by these two risk factors were investigated in selected patient groups in a comprehensive manner. We demonstrated that subtle changes in the morphologic and functional characteristics of the arterial wall and cognitive performance could already be detected in recently diagnosed hypertensive patients. These fine alterations may be the first signs of the devastating complications of long-standing hypertension.
Of note, when hyperlipidemia was associated with hypertension, a more pronounced deterioration of the vasculature could be detected, which underscores the importance of prompt recognition and appropriate treatment of both risk factors. These results can particularly be exploited during the everyday clinical practice, where borderline changes of BP or LDL-C levels are often neglected. Our study also points out that monitoring of individuals for high $\mathrm{BP}$ and serum lipid levels is essential not only in the apparently ill, but also in the seemingly healthy, asymptomatic subjects as well. Education of these individuals facilitates an early alert for their already existing risk factors, and thus, can not only contribute to a successful treatment, but may also prevent further impairments. In the future, screening evaluation studies may be necessary to assess economical aspects of a systematic, widespread screening of the population for these existing risk factors.

\section{Acknowledgments}

We would like to thank and express our sincere appreciation for the Cívis Company, the HUNÉP Universal Building Corp., and the Debrecen Police Department for encouraging their personnel to participate in our study as healthy volunteers. Special thanks to Józsefné Borók for her excellent technical assistance.

\section{References}

1. De Backer G, Ambrosioni E, Borch-Johnsen K, Brotons C, Cifkova R, Dallongeville J, et al. European guidelines on cardiovascular disease prevention in clinical practice. Third Joint Task Force of European and Other Societies on Cardiovascular Disease Prevention in Clinical Practice. Eur Heart J 2003;24(17):1601-10.

2. Lewington S, Clarke R, Qizilbash N, Peto R, Collins R. Age-specific relevance of usual blood pressure to vascular mortality: a meta-analysis of individual data for one million adults in 61 prospective studies. Lancet 2002;360(9349):1903-13.

3. Papademetriou V. Hypertension and cognitive function. Blood pressure regulation and cognitive function: a review of the literature. Geriatrics 2005;60(1):20-2. 4.

4. Messerli FH, Williams B, Ritz E. Essential hypertension. Lancet 2007;370(9587):591-603.

5. Badimon L, Vilahur G. LDL-cholesterol versus HDLcholesterol in the atherosclerotic plaque: inflammatory resolution versus thrombotic chaos. Ann N Y Acad Sci 2012;1254:18-32.

6. Crouse JR 3rd, Raichlen JS, Riley WA, Evans GW, Palmer MK, O'Leary DH, et al. Effect of rosuvastatin on progression of carotid intima-media thickness in low-risk individuals with subclinical atherosclerosis: the METEOR Trial. JAMA 2007;297(12):1344-53. 
7. Kivipelto M, Helkala EL, Hanninen T, Laakso MP, Hallikainen M, Alhainen K, et al. Midlife vascular risk factors and late-life mild cognitive impairment: a population-based study. Neurology 2001;56(12): 1683-9.

8. Whitmer RA, Sidney S, Selby J, Johnston SC, Yaffe K. Midlife cardiovascular risk factors and risk of dementia in late life. Neurology 2005;64(2):277-81.

9. Dufouil C, Richard F, Fievet N, Dartigues JF, Ritchie K, Tzourio C, et al. APOE genotype, cholesterol level, lipid-lowering treatment, and dementia: the ThreeCity Study. Neurology 2005;64(9):1531-8.

10. Martin SS, Blumenthal RS, Miller M. LDL cholesterol: the lower the better. Med Clin North Am 2012;96(1): 13-26.

11. Lewis SJ. Lipid-lowering therapy: who can benefit? Vasc Health Risk Manag 2011;7:525-34.

12. Reiner Z, Catapano AL, De Backer G, Graham I, Taskinen MR, Wiklund O, et al. ESC/EAS Guidelines for the management of dyslipidaemias: the Task Force for the management of dyslipidaemias of the European Society of Cardiology (ESC) and the European Atherosclerosis Society (EAS). Eur Heart J 2011;32(14): 1769-818.

13. Mancia G, Fagard R, Narkiewicz K, Redon J, Zanchetti A, Bohm M, et al. 2013 ESH/ESC Guidelines for the management of arterial hypertension: the Task Force for the management of arterial hypertension of the European Society of Hypertension (ESH) and of the European Society of Cardiology (ESC). Eur Heart J 2013;34(28):2159-219.

14. Horvath IG, Nemeth A, Lenkey Z, Alessandri N, Tufano F, Kis $\mathrm{P}$, et al. Invasive validation of a new oscillometric device (Arteriograph) for measuring augmentation index, central blood pressure and aortic pulse wave velocity. J Hypertens 2010;28(10):2068-75.

15. Baulmann J, Schillings U, Rickert S, Uen S, Dusing R, Illyes $\mathrm{M}$, et al. A new oscillometric method for assessment of arterial stiffness: comparison with tonometric and piezo-electronic methods. J Hypertens 2008; 26(3):523-8.

16. Jatoi NA, Mahmud A, Bennett K, Feely J. Assessment of arterial stiffness in hypertension: comparison of oscillometric (Arteriograph), piezoelectronic (Complior) and tonometric (SphygmoCor) techniques. J Hypertens 2009;27(11):2186-91.

17. Kovacs KR, Szekeres CC, Bajko Z, Csapo K, Molnar S, Olah L, et al. Cerebro- and cardiovascular reactivity and neuropsychological performance in hypertensive patients. J Neurol Sci 2010;299(1-2):120-5.

18. Blumenthal JA, Madden DJ, Pierce TW, Siegel WC, Appelbaum M. Hypertension affects neurobehavioral functioning. Psychosom Med 1993;55(1):44-50.

19. Vicario A, Martinez CD, Baretto D, Diaz Casale A, Nicolosi L. Hypertension and cognitive decline: impact on executive function. J Clin Hypertens (Greenwich) 2005;7(10):598-604.

20. Hajjar I, Kritchevsky S, Newman AB, Li R, Yaffe K, Simonsick EM, et al. Renin angiotensin system gene polymorphisms modify angiotensin-converting enzyme inhibitors' effect on cognitive function: the health, aging and body composition study. J Am Geriatr Soc 2010;58(6):1035-42.

21. Hajjar I, Hart M, Chen YL, Mack W, Milberg W, Chui $\mathrm{H}$, et al. Effect of antihypertensive therapy on cognitive function in early executive cognitive impairment: a double-blind randomized clinical trial. Arch Intern Med 2012;172(5):442-4.

22. Fogari R, Mugellini A, Zoppi A, Lazzari P, Destro M, Rinaldi A, et al. Effect of telmisartan/hydrochlorothiazide vs lisinopril/hydrochlorothiazide combination on ambulatory blood pressure and cognitive function in elderly hypertensive patients. J Hum Hypertens 2006; 20(3):177-85.

23. Suhr JA, Stewart JC, France CR. The relationship between blood pressure and cognitive performance in the Third National Health and Nutrition Examination Survey (NHANES III). Psychosom Med 2004;66(3): 291-7.

24. Hajjar I, Hart M, Chen YL, Mack W, Novak V, C Chui $\mathrm{H}$, et al. Antihypertensive therapy and cerebral hemodynamics in executive mild cognitive impairment: results of a pilot randomized clinical trial. J Am Geriatr Soc 2013;61(2):194-201.

25. Tanabe P, Persell SD, Adams JG, McCormick JC, Martinovich Z, Baker DW. Increased blood pressure in the emergency department: pain, anxiety, or undiagnosed hypertension? Ann Emerg Med 2008;51(3):221-9.

26. Chaves EC, Cade NV. [Anxiety effects on blood pressure of women with hypertension]. Rev Lat Am Enfermagem 2004;12(2):162-7.

27. Knecht S, Wersching H, Lohmann H, Berger K, Ringelstein EB. How much does hypertension affect cognition?: explained variance in cross-sectional analysis of non-demented community-dwelling individuals in the SEARCH study. J Neurol Sci 2009;283(1-2): $149-52$.

28. Matoso JM, Santos WB, Moreira Ide F, Lourenco RA, Correia ML. Elderly hypertensives show decreased cognitive performance compared with elderly normotensives. Arq Bras Cardiol 2013;100(5):444-51.

29. Bruno RM, Palagini L, Gemignani A, Virdis A, Di Giulio A, Ghiadoni L, et al. Poor sleep quality and resistant hypertension. Sleep Med 2013;14(11):1157-63.

30. Saboya PM, Zimmermann PR, Bodanese LC. Association between anxiety or depressive symptoms and arterial hypertension, and their impact on the quality of life. Int J Psychiatry Med 2010;40(3):307-20.

31. Cohen J, Sedlacek K. Attention and autonomic selfregulation. Psychosom Med 1983;45(3):243-57. 
32. Parnetti L, Mecocci P, Petrini A, Longo A, Buccolieri A, Senin U. Neuropsychological results of long-term therapy with oxiracetam in patients with dementia of Alzheimer type and multi-infarct dementia in comparison with a control group. Neuropsychobiology 1989;22(2):97-100.

33. Pall D, Settakis G, Katona E, Csiba L, Kakuk G, Limburg M, et al. Increased common carotid artery intima media thickness in adolescent hypertension: results from the Debrecen Hypertension study. Cerebrovasc Dis 2003;15(3):167-72.

34. Amer MS, Elawam AE, Khater MS, Omar OH, Mabrouk RA, Taha HM. Association of high-sensitivity C-reactive protein with carotid artery intima-media thickness in hypertensive older adults. J Am Soc Hypertens 2011;5(5):395-400.

35. Vladimirova-Kitova L, Terzieva D, Marinov B. Intimamedia thickness and flow-mediated vasodilation in asymptomatic subjects with newly detected severe hypercholesterolemia. Echocardiography 2009;26(9): 1060-8.

36. Li C, Engstrom G, Berglund G, Janzon L, Hedblad B. Incidence of ischemic stroke in relation to asymptomatic carotid artery atherosclerosis in subjects with normal blood pressure. A prospective cohort study. Cerebrovasc Dis 2008;26(3):297-303.

37. Nürnberger J, Keflioglu-Scheiber A, Opazo Saez AM, Wenzel RR, Philipp T, Schafers RF. Augmentation index is associated with cardiovascular risk. J Hypertens 2002;20(12):2407-14.

38. Wilkinson IB, Prasad K, Hall IR, Thomas A, MacCallum H, Webb DJ, et al. Increased central pulse pressure and augmentation index in subjects with hypercholesterolemia. J Am Coll Cardiol 2002;39(6): 1005-11.

39. Safar H, Mourad JJ, Safar M, Blacher J. Aortic pulse wave velocity, an independent marker of cardiovascular risk. Arch Mal Coeur Vaiss 2002;95(12):1215-8.

40. The Reference Values for Arterial Stiffness' Collaboration. Determinants of pulse wave velocity in healthy people and in the presence of cardiovascular risk factors: 'establishing normal and reference values'. Eur Heart J 2010;31(19):2338-50.

41. Sekikawa A, Shin C, Curb JD, Barinas-Mitchell E, Masaki K, El-Saed A, et al. Aortic stiffness and calcification in men in a population-based international study. Atherosclerosis 2012;222(2):473-7.

42. Lemarie CA, Tharaux PL, Lehoux S. Extracellular matrix alterations in hypertensive vascular remodeling. J Mol Cell Cardiol 2010;48(3):433-9.

43. Jiang L, Zhang J, Monticone RE, Telljohann R, Wu J, Wang M, et al. Calpain-1 regulation of matrix metalloproteinase 2 activity in vascular smooth muscle cells facilitates age-associated aortic wall calcification and fibrosis. Hypertension 2012;60(5):1192-9.
44. Mizuguchi Y, Oishi Y, Miyoshi H, Iuchi A, Nagase N, Oki T. Telmisartan improves morphologic and functional changes in both left ventricular myocardium and carotid arterial wall in patients with hypertension: assessment by tissue Doppler imaging and carotid ultrasonography. Echocardiography 2010;27(7):864-72.

45. Napoli C, Bruzzese G, Ignarro LJ, Crimi E, de Nigris F, Williams-Ignarro $\mathrm{S}$, et al. Long-term treatment with sulfhydryl angiotensin-converting enzyme inhibition reduces carotid intima-media thickening and improves the nitric oxide/oxidative stress pathways in newly diagnosed patients with mild to moderate primary hypertension. Am Heart J 2008;156(6):1154.e1-8.

46. Ichihara A, Kaneshiro Y, Sakoda M, Takemitsu T, Itoh $\mathrm{H}$. Add-on amlodipine improves arterial function and structure in hypertensive patients treated with an angiotensin receptor blocker. J Cardiovasc Pharmacol 2007;49(3):161-6.

47. Jekell A, Malmqvist K, Wallen NH, Mortsell D, Kahan T. Markers of inflammation, endothelial activation, and arterial stiffness in hypertensive heart disease and the effects of treatment: results from the SILVHIA study. J Cardiovasc Pharmacol 2013;62(6):559-66.

48. Debette S, Seshadri S, Beiser A, Au R, Himali JJ, Palumbo $\mathrm{C}$, et al. Midlife vascular risk factor exposure accelerates structural brain aging and cognitive decline. Neurology 2011;77(5):461-8.

49. Sierra C, De La Sierra A, Salamero M, Sobrino J, GomezAngelats E, Coca A. Silent cerebral white matter lesions and cognitive function in middle-aged essential hypertensive patients. Am J Hypertens 2004;17(6):529-34.

50. Frishman WH. Are antihypertensive agents protective against dementia? A review of clinical and preclinical data. Heart Dis 2002;4(6):380-6.

51. Gupta R, Solanki RK, Pathak V. Blood pressure is associated with cognitive impairment in young hypertensives. World J Biol Psychiatry 2008;9(1):43-50.

52. Waldstein SR. Hypertension and neuropsychological function: a lifespan perspective. Exp Aging Res 1995; 21(4):321-52.

53. Fredrikson M, Matthews KA. Cardiovascular responses to behavioral stress and hypertension: a meta-analytic review. Annals of Behaviorul Medicine 1990;12:30-9.

54. Waldstein SR, Manuck SB, Ryan CM, Muldoon MF. Neuropsychological correlates of hypertension: review and methodologic considerations. Psychol Bull 1991; 110(3):451-68.

55. Park SH, Kim JH, Choi KH, Jang YJ, Bae SS, Choi BT, et al. Hypercholesterolemia accelerates amyloid betainduced cognitive deficits. Int J Mol Med 2013;31(3): 577-82.

56. Frisardi V, Solfrizzi V, Seripa D, Capurso C, Santamato A, Sancarlo D, et al. Metabolic-cognitive syndrome: a crosstalk between metabolic syndrome and Alzheimer's disease. Ageing Res Rev 2010;9(4):399-417. 
57. Miller RE, Shapiro AP, King HE, Ginchereau EH, Hosutt JA. Effect of antihypertensive treatment on the behavioral consequences of elevated blood pressure. Hypertension 1984;6(2 Pt 1):202-8.

58. Hanon O, Berrou JP, Negre-Pages L, Goch JH, Nadhazi Z, Petrella R, et al. Effects of hypertension therapy based on eprosartan on systolic arterial blood pressure and cognitive function: primary results of the Observational Study on Cognitive function And Systolic Blood Pressure Reduction open-label study. J Hypertens 2008;26(8):1642-50.

59. Levi Marpillat N, Macquin-Mavier I, Tropeano AI, Bachoud-Levi AC, Maison P. Antihypertensive classes, cognitive decline and incidence of dementia: a network meta-analysis. J Hypertens 2013;31(6):1073-82.
60. Pilgrim JA. Psychological aspects of high and low blood pressure. Psychol Med 1994;24(1):9-14.

61. Vetere G, Ripaldi L, Ais E, Korob G, Kes M, Villamil A. [Prevalence of anxiety disorders in patients with essential hypertension]. Vertex 2007; 18(71):20-5.

62. Bajko Z, Szekeres CC, Kovacs KR, Csapo K, Molnar S, Soltesz P, et al. Anxiety, depression and autonomic nervous system dysfunction in hypertension. J Neurol Sci 2012;317(1-2):112-6.

63. Paterniti S, Alperovitch A, Ducimetiere P, Dealberto MJ, Lepine JP, Bisserbe JC. Anxiety but not depression is associated with elevated blood pressure in a community group of French elderly. Psychosom Med 1999;61(1): $77-83$. 


\section{AUTHOR QUERY FORM}

\begin{tabular}{|c|c|c|}
\hline$\frac{\text { ELSEVIER }}{\text { ELS }}$ & Journal: JASH & $\begin{array}{l}\text { Please e-mail or fax your responses and any corrections to: } \\
\text { E-mail: Daniel.Jagadisan@elsevier.com } \\
\text { Fax: +91 } 4445964899\end{array}$ \\
\hline
\end{tabular}

Dear Author,

Please check your proof carefully and mark all corrections at the appropriate place in the proof (e.g., by using on-screen annotation in the PDF file) or compile them in a separate list. Note: if you opt to annotate the file with software other than Adobe Reader then please also highlight the appropriate place in the PDF file. To ensure fast publication of your paper please return your corrections within 48 hours.

For correction or revision of any artwork, please consult http://www.elsevier.com/artworkinstructions.

Any queries or remarks that have arisen during the processing of your manuscript are listed below and highlighted by flags in the proof.

\begin{tabular}{|c|c|}
\hline $\begin{array}{l}\text { Location } \\
\text { in article }\end{array}$ & $\begin{array}{l}\text { Query / Remark: Click on the } Q \text { link to find the query's location in text } \\
\text { Please insert your reply or correction at the corresponding line in the proof }\end{array}$ \\
\hline & $\begin{array}{l}\text { If there are any drug dosages in your article, please verify them and indicate that you have done so by } \\
\text { initialing this query }\end{array}$ \\
\hline Q1 & The article title has been modified. Please check, and correct if necessary. \\
\hline Q2 & Please provide the name of the 'department' for affiliations ' $\mathrm{d}$ and e', if any. \\
\hline Q3 & $\begin{array}{l}\text { Please verify if grant sponsor and number linked for "TÁMOP-4.2.1/B-09/1/KONV-2010-0007" is correct. } \\
\text { Please make changes if necessary, or provide the grant sponsor/number separately. }\end{array}$ \\
\hline Q4 & Please provide the grant number for 'European Union', if any. \\
\hline Q5 & Please provide the grant number for 'European Social Fund', if any. \\
\hline Q6 & $\begin{array}{l}\text { Please note that the representations "LDL-C", "HDL-C", and T-C" can be changed to "LDL-C", "HDL- } \\
\text { C", and "T-C" in the article. Please verify if it can be changed. }\end{array}$ \\
\hline Q7 & $\begin{array}{l}\text { Please note the edits made inside the parenthesis in the 'Results' section for redundancy. Please check and } \\
\text { clarify the edits and make changes if necessary. }\end{array}$ \\
\hline Q8 & Please check the edits made to the expansion of "RAVLT" and correct if necessary. \\
\hline Q9 & $\begin{array}{l}\text { Please note that bold style is not allowed in the tables. Hence please provide a significance for the bold } \\
\text { values in the legend of 'Table 3' if any. }\end{array}$ \\
\hline Q10 & Please confirm that given names and surnames have been identified correctly. \\
\hline
\end{tabular}




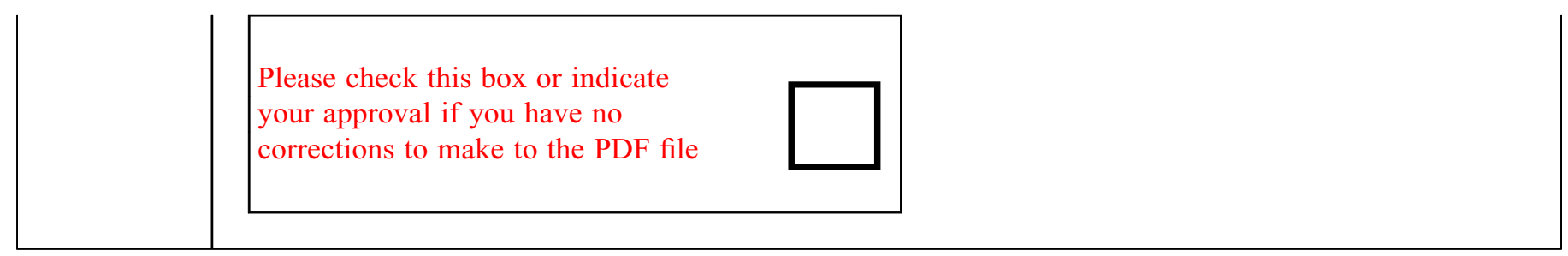

Thank you for your assistance. 